\title{
Electrospun Antimony Tin Oxide Nanofibers with Superior Stability as Anode Material for Li-ion Batteries
}

\author{
Ning Zhao ${ }^{1,2,3}$,Libo Deng $^{2}$,Dawei Luo ${ }^{3}$,Shuting He ${ }^{1}$ and Peixin Zhang ${ }^{1,2, *}$ \\ ${ }^{1}$ School of Materials \& Mineral Resources, Xi'an University of Architecture and Technology, Xi'an, \\ Shanxi 710055, P.R China \\ ${ }^{2}$ College of Chemistry and Environmental Engineering, Shenzhen University, Shenzhen 518060, \\ China \\ ${ }^{3}$ School of chemistry and biological application, Shenzhen Polytechnic,Shenzhen 518000,China \\ *E-mail: pxzhang@szu.edu.cn
}

doi: $10.20964 / 2018.11 .36$

Received: 23 July 2018 / Accepted: 8 September 2018 / Published: 1 October 2018

\begin{abstract}
Tin oxide $\left(\mathrm{SnO}_{2}\right)$ is a promising alternative material to replace graphite as an anode material for lithium ion battery (LIB). However, bulky neat $\mathrm{SnO}_{2}$ still suffers from serious pulverization and rapid decay of capacity during charging and discharging. In this study, to enhance the cyclic stability and rate performance of $\mathrm{SnO}_{2}$-based anode, antimony tin oxide (ATO)-containing nanofibers were synthesized by a two-step process in this work, including electrospinning of $\mathrm{SnCl}_{2} / \mathrm{SbCl}_{3} / \mathrm{PVP}$ and calcination at $400^{\circ} \mathrm{C}-600^{\circ} \mathrm{C}$ in air. The electrospun fibers developed from solid to hollow structures through a Kirkendall diffusion process. All ATO nanofibers treated at different temperatures showed an extraordinary initial capacities, in the range of $1563 \mathrm{mAhg}^{-1}-1711 \mathrm{mAhg}^{-1}$ during the first discharge. Moreover, the fibers calcinated at $400{ }^{\circ} \mathrm{C}$ exhibited excellent cyclic stability, namely the capacity at the $200^{\text {th }}$ cycle was $730 \mathrm{mAhg}^{-1}$ at a current density of $0.2 \mathrm{Ag}^{-1}$, which was $76 \%$ of its capacity at the $2^{\text {nd }}$ cycle. In addition, this material also displayed excellent rate performance, delivering $327 \mathrm{mAhg}^{-1}$ at $3.2 \mathrm{Ag}^{-1}$ after 60 cycles. These values were superior to those calcinated at $600^{\circ} \mathrm{C}$, Because of its reduced volume, the carbon matrix provides a large surface area and a short diffusion length in the treated ATO fibers. provided by the carbon matrix in the $400^{\circ} \mathrm{C}$-treated ATO fibers. These results revealed the importance of combining the buffering carbon phase with the nano-fibrous structure for the improvement of $\mathrm{SnO}_{2}$-based electrode, and would pave the way for further enhancing the performance of anodes for LIBs.
\end{abstract}

Keywords: Antimony tin oxide; Hollow nanofibers; Anode; Li-ion battery 
(C) 2018 The Authors. Published by ESG (www.electrochemsci.org). This article is an open access article distributed under the terms and conditions of the Creative Commons Attribution license (http://creativecommons.org/licenses/by/4.0/). 